Article

\title{
One-Dimensional Helical Homochiral Metal-Organic Framework Built from 2,2'-Dihydroxy-1,1'-binaphthyl-3,3'- dicarboxylic Acid
}

\author{
Koichi Tanaka $^{1, *}$, Yuki Kikumoto ${ }^{1}$ and Motoo Shiro ${ }^{2}$ \\ 1 Department of Chemistry and Materials Engineering, Faculty of Chemistry, Materials and \\ Bioengineering, Kansai University, Suita, Osaka 564-8680, Japan \\ 2 Rigaku X-ray Laboratory, 3-9-12 Matsubara-cho, Akishima, Tokyo 196-8666, Japan; \\ E-Mail: shiro@rigaku.co.jp
}

* Author to whom correspondence should be addressed; E-Mail: ktanaka@kansai-u.ac.jp; Tel.: +81-06-6368-0861; Fax: +81-06-6368-0861.

Received: 17 August 2011; in revised form: 19 September 2011 / Accepted: 31 October 2011 / Published: 1 November 2011

\begin{abstract}
A homochiral metal-organic framework (MOF) based on enantiopure (R)-2,2'-dihydroxy-1,1'-binaphthyl-3,3'-dicarboxylic acid was synthesized. X-ray crystal diffraction studies revealed that the MOF adopts a one-dimensional infinite right-handed helical tubular structure along the $a$-axis, which serves as a host for the inclusion of guest dimethylformamide (DMF) molecules.
\end{abstract}

Keywords: homochiral metal-organic framework; chiral ligand; helix structure; one-dimensional network

\section{Introduction}

The field of metal-organic frameworks (MOFs) has grown explosively in recent years [1-8]; numerous studies have been reported owing to the potential applications of MOFs in gas storage [9-15], separation [16-23], luminescent materials [24-32], and heterogeneous catalysis [33-41]. While several MOFs have been discovered so far, only a few examples of chiral MOFs for enantiomer separations or heterogeneous asymmetric catalysis have been investigated [42]. We recently reported the synthesis of a 
novel two-dimensional homochiral MOF, $(R)$-MOF-1, from $(R)$-2,2'-dihydroxy-1,1'-binaphthyl-5,5'dicarboxylic acid (1) (Scheme 1) and its application as an effective catalyst for the asymmetric ring-opening reaction of epoxide with amine [43] and the alcoholytic kinetic resolution of styrene oxide under heterogeneous conditions [44]. The helical structures of MOFs have also attracted considerable attention because of not only their intriguing structures, but also their potential applications in chiral recognition, nonlinear optical materials, and asymmetric catalysis. Over the past two decades, several MOFs containing single-, double-, and multi-stranded helices have been constructed and recently reviewed [45]. For example, one-dimensional helical metal-organic framework built from a chiral octahydrobinaphthalene-derived dicarboxylic acid showed the intense broad photoluminescence emission in the solid state [46]. Tridentate chiral Schiff base ligands has been found to form 1D helical framework which allow highly enantioselective separation of racemic secondary alcohols by inclusion crystallization [47]. Chiral binaphthylbisbipyridine-based copper (I) coordination polymer gels for use as catalysts in 1,3-dipolar Huisgen cycloaddition reactions are also reported [48]. Herein, we report the synthesis and X-ray crystal structure of the one-dimensional helical homochiral MOF, $(R)$-MOF-2, constructed from (R)-2,2'-dihydroxy-1,1'-binaphthyl-3,3'-dicarboxylic acid (2) (Scheme 2).

Scheme 1. Synthesis of $(R)-M O F-1$.

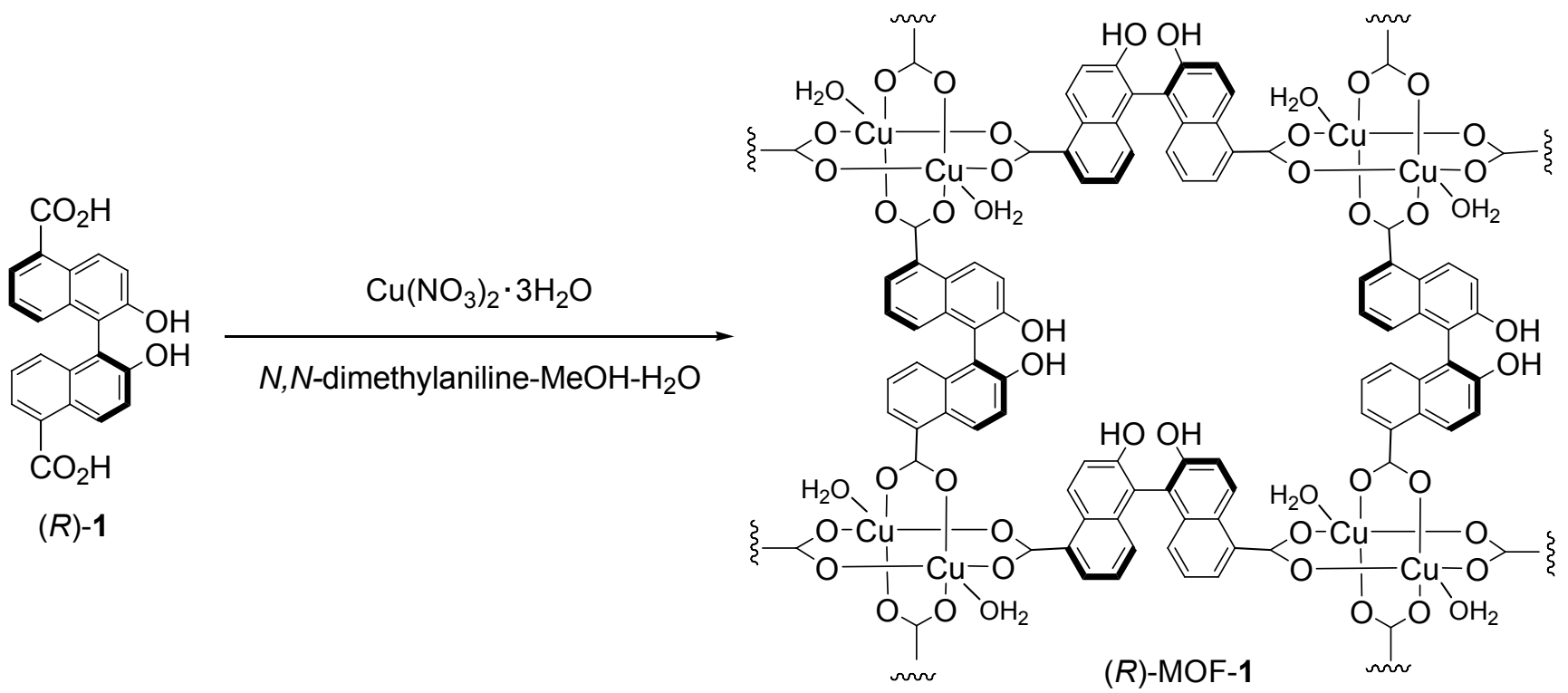

Scheme 2. Synthesis of (R)-MOF-2.<smiles></smiles>

$(R)-2$<smiles>CCCCOC(=O)c1cc2ccccc2c(-c2c(O)c(C(=O)OCC)cc3ccccc23)c1OC(C)C</smiles>

$(R)-M O F-2$ 


\section{Experimental Section}

General: ${ }^{1} \mathrm{H}-\mathrm{NMR}$ spectra were recorded on a JEOL JNM-GSX 400 spectrometer with tetramethylsilane (TMS) as the internal standard. IR spectra were recorded with a JASCO FT-IR 4100 spectrometer. Thermogravimetric (TG) analyses were performed on a Rigaku TG8120 instrument. Solid-state circular dichroism (CD) spectra were recorded as $\mathrm{KBr}$ pellets on a JASCO J-820 CD system.

Synthesis of enantiopure $2,2^{\prime}$-dihydroxy-1,1'-binaphthyl-3,3'-dicarboxylic acid (2): $(R)$ - and (S)-2,2'-dihydroxy-1,1'-binaphthyl-3,3'-dicarboxylic acid (2) were synthesized according to the procedure previously reported by D. J. Cram et al. [49].

Synthesis of $\left[\mathrm{Mn}_{\mathbf{2}}((R)-\mathbf{1})_{\mathbf{2}}(\mathrm{DMF})_{\mathbf{4}}\left(\mathrm{H}_{\mathbf{2}} \mathrm{O}\right)_{\mathbf{4}}\right] \cdot \mathbf{2 D M F}$ : A mixture of $(R)-2,2^{\prime}$-dihydroxy-1,1'binaphthyl-3,3'-dicarboxylic acid (2) (78 $\mathrm{mg}, 0.2 \mathrm{mmol})$ and $\mathrm{MnCl}_{2} \cdot 4 \mathrm{H}_{2} \mathrm{O}$ (40 $\left.\mathrm{mg}, 0.2 \mathrm{mmol}\right)$ was dissolved in DMF $(1 \mathrm{~mL})$ and $\mathrm{H}_{2} \mathrm{O}(2 \mathrm{~mL})$, and then pyridine $(1 \mathrm{~mL})$ was added to the solution. The solution was stirred for $30 \mathrm{~min}$ at room temperature and then left for 3 days. Pale yellow prisms were obtained, filtered, and dried at room temperature to give $(R)$-MOF-2 $(132 \mathrm{mg})$. IR (KBr pellet, $\left.\mathrm{cm}^{-1}\right)$ : 3,402, 2,931, 1,655, 1,559, 1,505, 1,457, 1,392, 1,336, 1,309, 1,242, 1,101, 932, 874, 810, 755, 702.

X-ray analysis: X-ray single-crystal diffraction data for $(R)$-MOF-2 were collected on a Rigaku RAXIS RAPID imaging plate diffractometer using $\mathrm{Cu} \mathrm{K \alpha}$ radiation. Crystal data: Formula $\mathrm{C}_{62} \mathrm{H}_{74} \mathrm{Mn}_{2} \mathrm{~N}_{6} \mathrm{O}_{22}$, Formula weight 1365.17, Space group $P 2_{1}(\# 4), a=10.9585(3), b=25.2165(8)$, $c=11.8505(9) \AA, \beta=96.629(7)^{\circ}, V=3252.8(3) \AA^{3}, Z=2, \rho=1.394 \mathrm{~g} / \mathrm{cm}^{3}, 2 \theta_{\max }=136.4^{\circ}$, $R 1=0.0514$ (for 8372 reflections with $I>2 \sigma(\mathrm{I})), w R 2=0.1315$ (for 11,652 reflections), $\mathrm{GOF}=0.985$, Flack parameter $=0.009(4)$ (calculated using 5,571 Friedel pairs). The structure was solved by SHELXS97 and refined by SHELXL97. The absolute structure was deduced from the Flack parameter.

CCDC: 838075 . See http://www.rsc.org/suppdata/cc/........../ for crystallographic data in cif or other electric formats.

\section{Results and Discussion}

\subsection{Synthesis of Chiral MOF}

Chiral ligand $(R)$-2,2'-dihydroxy-1,1'-binaphthyl-3,3'-dicarboxylic acid (2) was prepared in good yield by the diastereomeric complexation of rac-2 with L-(+)-leucine methyl ester (Scheme 3). The CD spectra of $(R)-(+)$ - and $(S)-(-)-2$ in $\mathrm{CHCl}_{3}$ are shown in Figure 1.

Scheme 3. Optical resolution of rac-2.

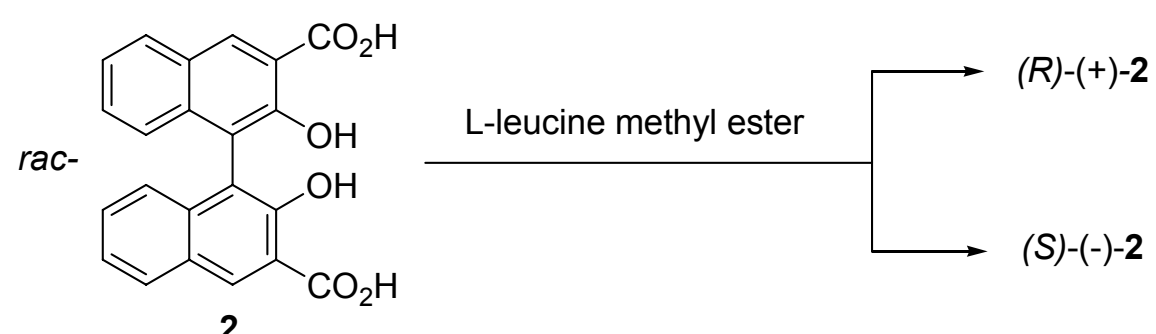


Figure 1. CD spectra of $(R)$ - and $(S)-2$ in $\mathrm{CHCl}_{3}$.

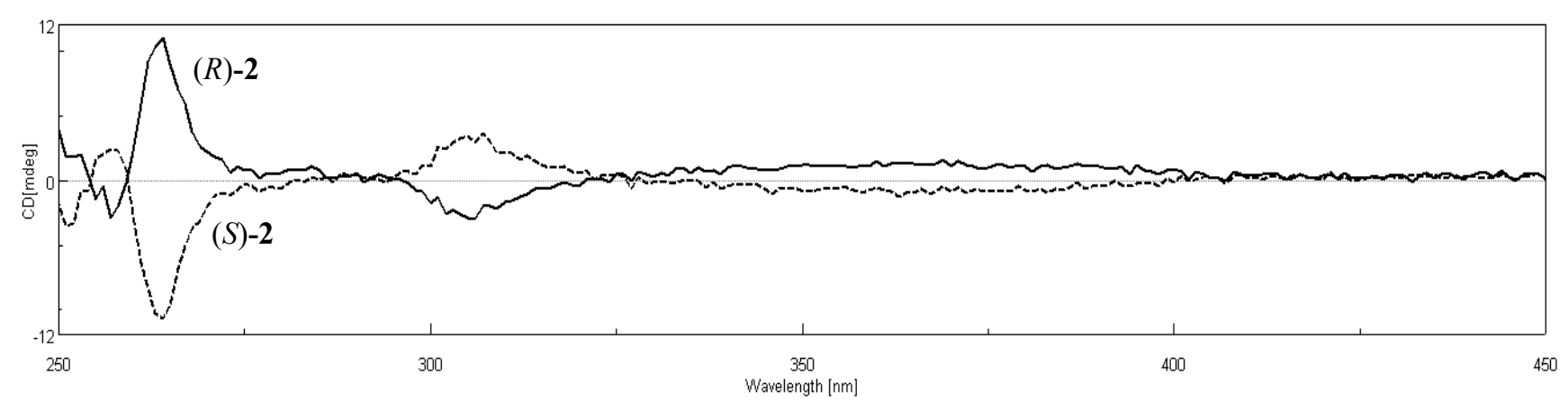

New homochiral $(R)$-MOF-2 $\left[\mathrm{Mn}_{2}((R)-\mathbf{1})_{2}(\mathrm{DMF})_{4}\left(\mathrm{H}_{2} \mathrm{O}\right)_{4}\right] \cdot 2 \mathrm{DMF}$ was synthesized by the reaction of $(R)-(+)-2$ and $\mathrm{MnCl}_{2} \cdot 4 \mathrm{H}_{2} \mathrm{O}$ in the presence of pyridine in DMF at room temperature. The product was characterized by IR spectroscopy, CD spectroscopy, thermogravimetric analysis (TGA), and $\mathrm{X}$-ray analysis. The IR spectra of $(R)$-MOF-2 exhibited peaks of $\mathrm{vOH}$ and $\mathrm{vCO}_{2}^{-}$at 3,401 and $1,559 \mathrm{~cm}^{-1}$, respectively. TGA showed that $(R)-\mathrm{MOF}-2$ loses $34.3 \%$ of its total weight in the range of $26-300{ }^{\circ} \mathrm{C}$, which is ascribed to the loss of six DMF and four water molecules per formula unit (calculated at $37.4 \%$ of the total weight) (Figure 2).

Figure 2. TG trace of $(R)-\mathrm{MOF}-2$.

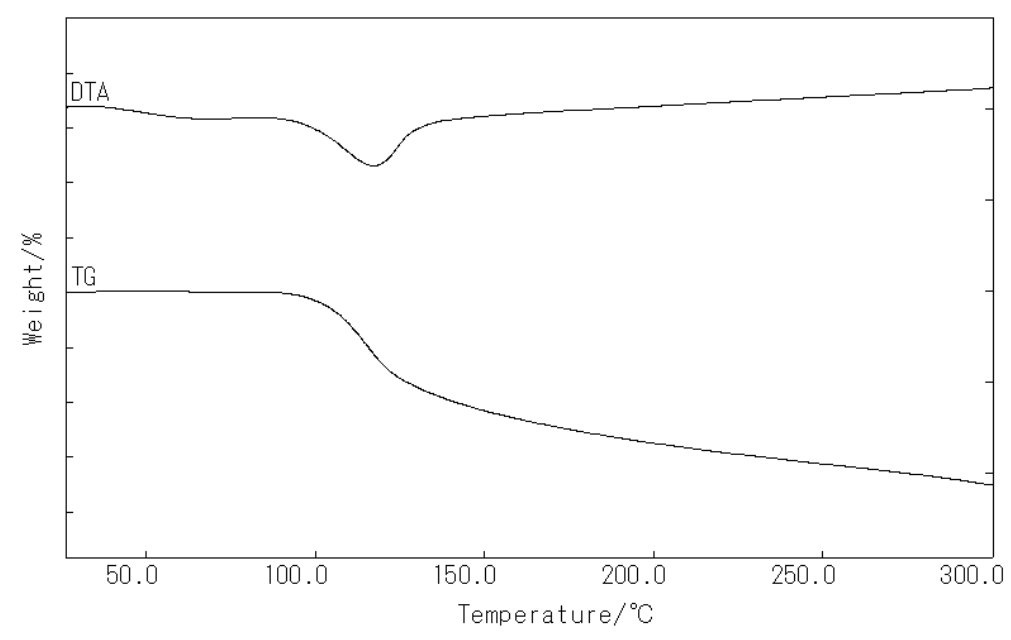

\subsection{Crystal Structure of (R)-MOF-2}

X-ray diffraction measurement revealed that $(R)$-MOF-2 crystallizes in a chiral space group of $P 2_{1}$. An asymmetric unit of $(R)$-MOF-2 contains two $\mathrm{Mn}^{2+}$ ions, two $(R)-2^{2-}$ groups, four DMF molecules, four water molecules, and two DMF guest molecules, as shown in Figure 3. The $\mathrm{Mn}^{2+}$ ion is coordinated by two $(R)-\mathbf{2}^{2-}$ groups, two DMF molecules, and two water molecules. The sixth coordination site of Mn1, although vacant in Figure 3, is occupied by $\mathrm{O} 11$ of the $(R)-2$ group lying in the next unit cell in the direction of $a$-axis. A helical chain composed of $-\mathrm{Mn}-(R)-2-\mathrm{Mn}-(R)-2-$ is thus formed in the right-handed form and extends along the $a$-axis as shown in Figure 4 . The guest molecules are bound to the water molecules by the hydrogen bonds of $\mathrm{O} 21-\mathrm{H} \ldots \mathrm{O} 18$ and O22-H...O19. 
Figure 3. Structure of $(R)-\mathrm{MOF}-2$ in an asymmetric unit and atomic numbering system. Hydrogen atoms, excluding those of water, are omitted for clarity.

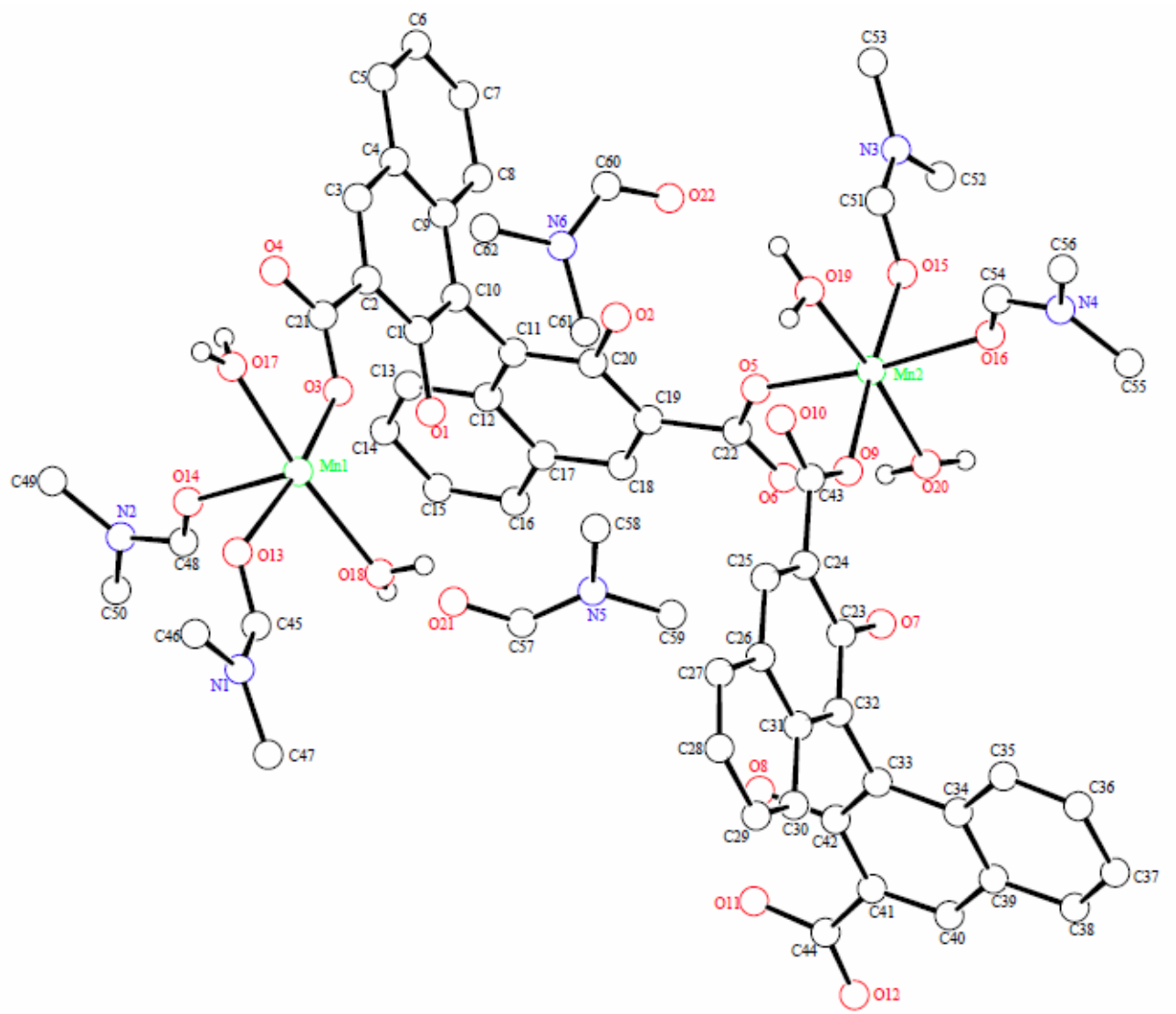

Figure 4. Right-handed helical structure in the crystal of $(R)$-MOF-2. The $a$-axis of the crystal is oriented vertically. All hydrogen atoms and guest molecules are omitted for clarity.

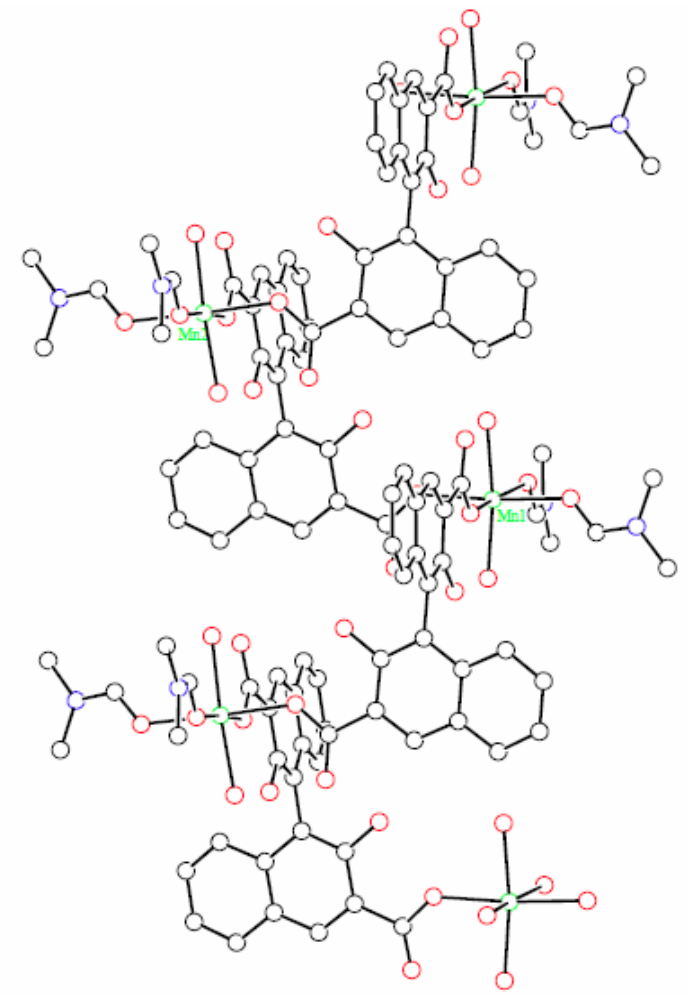


We also prepared $(S)$-MOF-2 using $(S)$-2 as the chiral ligand. As shown in Figure 5, the solid-state CD spectra of $(R)$ - and $(S)$-MOF-2 synthesized from $(R)$ - and $(S)$-2, respectively, are mirror images of each other, thus indicating that the helices built from $(R)$ - and $(S)-2$ are enantiomeric.

Figure 5. Solid-state CD spectra of $(R)$ - and $(S)-\mathrm{MOF}-2$ in $\mathrm{KBr}$ pellet.

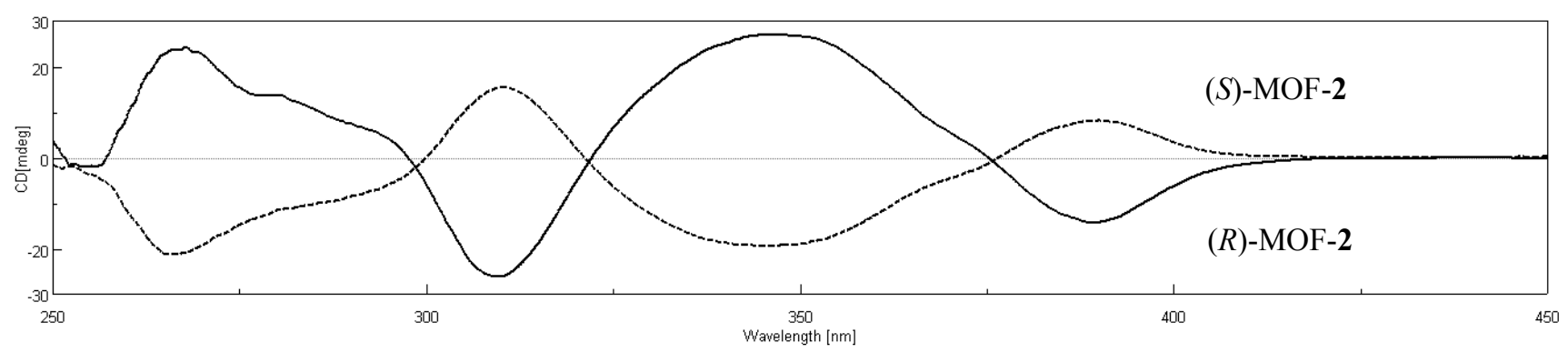

\section{Conclusions}

We have synthesized a one-dimensional helical homochiral MOF (MOF-2) using $\mathrm{MnCl}_{2}$ and $C_{2}$ symmetric chiral ligands $(R)$ - and $(S)-2$ as the building blocks. We are currently studying its potential applications in heterogeneous asymmetric catalysis and enantioselective separations.

\section{Acknowledgment}

We thank JASCO Corporation Tokyo Japan for help with solid-state CD spectral data collection.

\section{References}

1. Yaghi, O.M.; Li, H.; Davis, C.; Richardson, D.; Groy, T.L. Synthetic Strategies, Structure Patterns, and Emerging Properties in the Chemistry of Modular Porous Solids. Acc. Chem. Res. 1998, 31, 474-484.

2. Eddaoudi, M.; Moler, D.B.; Li, H.; Chen, B.; Reineke, T.M.; O’Keeffe, M.; Yaghi, O.M. Modular Chemistry: Secondary Building Units as a Basis for the Design of Highly Porous and Robust Metal-Organic Carboxylate Frameworks. Acc. Chem. Res. 2001, 34, 319-330.

3. Yaghi, O.M.; O'Keeffe, M.; Ockwig, N.M.; Chae, H.K.; Eddaoudi, M.; Kim, J. Reticular Synthesis and the Design of New Materials. Nature 2003, 423, 705-714.

4. Zhao, X.; Xiao, B.; Fletcher, A.J.; Thomas, K.M.; Bradshaw, D.; Rosseinsky, M.J. Hysteretic Adsorption and Desorption of Hydrogen by Nanoporous Metal-Organic Frameworks. Science 2004, 306, 1012-1015.

5. Ferey, G.; Mellot-Draznieks, C.; Serre, C.; Millange, F. Crystallized Frameworks with Giant Pores: Are There Limits to the Possible? Acc. Chem. Res. 2005, 38, 217-225.

6. Hill, R.J.; Long, D.L.; Champness, N.R.; Hubberstey, P.; Schroder, M. New Approaches to the Analysis of High Connectivity Materials: Design Frameworks Based upon $4^{4}$ - and $6^{3}$-Subnet Tectons. Acc. Chem. Res. 2005, 38, 335-348.

7. Wang, Z.; Chen, G.; Ding, K. Self-Supported Catalysts. Chem. Rev. 2009, 109, 322-359. 
8. Long, J.R.; Yaghi, O.M. The Pervasive Chemistry of Metal-Organic Frameworks. Chem. Soc. Rev. 2009, 38, 1213-1214.

9. Eddaoudi, M.; Kim, J.; Rosi, N.; Vodak, D.; Wachter, J.; O’Keeffe, M.; Yaghi, O.M. Systematic Design of Pore Size and Functionality in Isoreticular Metal-Organic Frameworks and Application in Methane Storage. Science 2002, 295, 469-472.

10. Seki, K.; Mori, W. Syntheses and Characterization of Microporous Coordination Polymers with Open Frameworks. J. Phys. Chem. B 2002, 106, 1380-1385.

11. Rowsell, J.L.C.; Millward, A.R.; Park, K.S.; Yaghi, O.M. Hydrogen Sorption in Functionalized Metal-Organic Frameworks. J. Am. Chem. Soc. 2004, 126, 5666-5667.

12. Matsuda, R.; Kitaura, R.; Kitagawa, S.; Kubota, Y.; Belosludov, R.V.; Kobayashi, T.C.; Sakamoto, H.; Chiba, T.; Takata, M.; Kawazoe, Y.; Mita, Y. Highly Controlled Acetylene Accommodation in a Metal-Organic Microporous Material. Nature 2005, 436, 238-241.

13. Wong-Foy, A.G.; Matzger, A.J.; Yaghi, O.M. Exceptional $\mathrm{H}_{2}$ Saturation Uptake in Microporous Metal-Organic Frameworks. J. Am. Chem. Soc. 2006, 128, 3494-3495.

14. Xiang, S.; Zhou, W.; Gallegos, J.M.; Liu, Y.; Chen, B.; Xiang, S.; Zhou, W.; Gallegos, J.M.; Liu, Y.; Chen, B. Methane Storage in Porous Metal-Organic Frameworks: Current Records and Future Perspectives. J. Am. Chem. Soc. 2009, 131, 12415-12419.

15. Chen, Z.; Xiang, S.; Arman, H.D.; Li, P.; Tidrow, S.; Zhao, D.; Chen, B. A Microporous Metal-Organic Framework with Immobilized - $\mathrm{OH}$ Functional Groups within the Pore Surfaces for Selective Gas Sorption. Eur. J. Inorg. Chem. 2010, 2010, 3745-3749.

16. Min, K.S.; Suh, M.P. Self-Assembly of 3-D Open-Framework Solids from Macrocyclic Complexes as Trifunctional Metal Building Block and Selective Guest Binding. Chem. Eur. J. 2001, 7, 303-313.

17. Uemura, K.; Kitagawa, S.; Kondo, M.; Fukui, K.; Kitaura, R.; Chang, H.C.; Mizutani, T. Novel Flexible Frameworks of Porous Cobalt(II) Coordination Polymers Which Show Selective Guest Adsorption Based on Switching of Hydrogen Bond Pairs of Amide Groups. Chem. Eur. J. 2002, 8, 3586-3600.

18. Bradshaw, D.; Prior, T.J.; Cussen, E.J.; Claridge, J.B.; Rosseinsky, M.J. Permanent Microporosity and Enantioselective Sorption in a Chiral Open Framework. J. Am. Chem. Soc. 2004, 126, 6106-6114.

19. Suslick, K.S.; Bhyrappa, P.; Chou, J.H.; Kosal, M.E.; Nakagaki, S.; Smithenry, D.W.; Wilson, S.R. Microporous Porphyrin Solids. Acc. Chem. Res. 2005, 38, 283-291.

20. Mueller, U.; Schubert, M.; Teich, F.; Puetter, H.; Schierle-Arndt, K.; Pastre, J. Metal-Organic Frameworks-Prospective Industrial Applications. J. Mater. Chem. 2006, 16, 626-636.

21. Pan, L.; Olson, D.H.; Ciemnolonski, L.R.; Heddy, R.; Li, J. Separation of Hydrocarbons with a Microporous Metal-Organic Framework. Angew. Chem. Int. Ed. 2006, 45, 616-619.

22. Horike, S.; Tanaka, D.; Nakagawa, K.; Kitagawa, S. Selective Guest Sorption in Interdigitated Porous Framework with Hydrophobic Pore Surfaces. Chem. Commun. 2007, doi: 10.1039/B703502K.

23. Couck, S.; Denayer, J.F.M.; Baron, G.V.; Remy, T.; Gascon, J.; Kapteijin, F. An Amine-Functionalized MIL-53 Metal-Organic Framework with Large Separation Power for $\mathrm{CO}_{2}$ and $\mathrm{CH}_{4}$. J. Am. Chem. Soc. 2009, 131, 6326-6327. 
24. Schlichte, K.; Kratzka, T.; Kaskel, S. Improved Synthesis, Thermal Stability and Catalytic Properties of the Metal Organic Framework $\mathrm{Cu}_{3}(\mathrm{BTC})_{2}$. Microporous Mesoporous Mater. 2004, $73,81-88$.

25. Wu, C.; Hu, A.; Zhang, L.; Lin, W. A Homochiral Porous Metal-Organic Framework for Highly Enantioselective Heterogeneous Asymmetric Catalysis. J. Am. Chem. Soc. 2005, 127, 8940-8941.

26. Alaerts, L.; Seguin, E.; Poelman, H.; Thibault-Starzyk, F.; Jacobs, P.A.; De Vos, D.E. Probing the Lewis Acidity and Catalytic Activity of the Metal-Organic Framework $\left[\mathrm{Cu}_{3}(\mathrm{btc})_{2}\right]$. Chem. Eur. J. 2006, 12, 7353-7363.

27. Hasegawa, S.; Horike, S.; Furukawa, S.; Mochizuki, K.; Kinoshita, Y.; Kitagawa, S. A Three Dimensional Porous Coordination Polymer Functionalized with Amide Groups Based on Tridentate Ligand: Selective Sorption and Catalysis. J. Am. Chem. Soc. 2007, 129, 2607-2614.

28. Proch, S.; Hermansdorfer, J.; Kempe, R.; Kern, C.; Jess, A.; Seyfarth, L.; Senker, J. Pt@MOF-177: Synthesis, Room-Temperature Hydrogen Storage and Oxidation Catalysis. Chem. Eur. J. 2008, 14, 8204-8212.

29. Ravon, U.; Domine, M.E.; Gaudillere, C.; Desmartin-Chomel, A.; Farrusseng, D. MOFs as Acid Catalysts with Shape Selectivity Properties. New. J. Chem. 2008, 32, 937-940.

30. Horike, S.; Dinca, M.; Tamaki, K.; Long, J.R. Size-Selective Lewis-Acid Catalysis in a Microporous Metal-Organic Framework with Exposed $\mathrm{Mn}^{2+}$ Coordination Sites. J. Am. Chem. Soc. 2008, 130, 5854-5855.

31. Henschel, A.; Gedrich, K.; Kraehnert, R.; Kaskel, S. Catalytic Properties of MIL-101. Chem. Commun. 2008, doi: 10.1039/B718371B.

32. Allendorf, M.D.; Bauer, C.A.; Bhakta, R.K.; Houk, R.J.T. Luminescent Metal-Organic Frameworks. Chem. Soc. Rev. 2009, 38, 1330-1352.

33. Evans, O.R.; Ngo, H.L.; Lin, W. Chiral Porous Solids Based on Lamellar Lanthanide Phosphonates. J. Am. Chem. Soc. 2001, 123, 10395-10396.

34. Cui, Y.; Evance, O.R.; Ngo, L.H.; White, P.S.; Lin, W. Rational Design of Homochiral Solids Based on 2D Metal Carboxylates. Angew. Chem. Int. Ed. 2002, 41, 1159-1162.

35. Bradshaw, D.; Prior, T.J.; Cussen, E.J.; Claridge, J.B.; Rossensky, M.J. Permanent Microporosity and Enantioselective Sorption in a Chiral Open Framework. J. Am. Chem. Soc. 2004, 126, 6106-6114.

36. Wu, C.D.; Hu, A.; Zhang, L.; Lin, W. A Homochiral Porous Metal-Organic Framework for Highly Enantioselective Heterogeneous Asymmetric Catalysis. J. Am. Chem. Soc. 2005, 127, 8940-8941.

37. Wu, C.; Lin, W. A Chiral Porous 3D Metal-Organic Framework with an Unprecdented 4-Connected Network Topology. Chem. Commun. 2005, doi: 10.1039/B505916J.

38. Dybtsev, D.N.; Nuzhdin, A.L.; Chun, H.; Bryliakov, K.P.; Talsi, E.P.; Fedin, V.P.; Kim, K. A Homochiral Metal-Organic Material with Permanent Porosity, Enantioselective Sorption Properties, and Catalytic Activity. Angew. Chem. Int. Ed. 2006, 45, 916-920.

39. Cho, S.; Ma, B.; Nguyen, S.T.; Hupp, J.T.; Albrecht-Schmitt, T.E. A Metal-Organic Framework Material that Functions as an Enantioselective Catalyst for Olefin Epoxidation. Chem. Commun. 2006, doi: 10.1039/B600408C. 
40. Ingleson, M.J.; Barrio, J.P.; Bacsa, J.; Dickinson, C.; Park, H.; Rosseinsky, M.J. Generation of a Solid Brønsted Acid Site in a Chiral Framework. Chem. Commun. 2008, doi: 10.1039/B718443C

41. Liao, T.; Ling, Y.; Chen, Z.; Zhao, Y.; Weng, L. A Rutile-Type Porous Zinc (II)-Phosphonocarboxylate Framework: Local Proton Transfer and Size-Selected Catalysis. Chem. Commun. 2010, 46, 1100-1102.

42. Ma, L.; Abney, C.; Lin, W. Enantioselective Catalysis with Homochiral Metal-Organic Frameworks. Chem. Soc. Rev. 2009, 38, 1248-1256.

43. Tanaka, K.; Oda, S.; Shiro, M. A Novel Chiral Porous Metal-Organic Framework: Asymmetric Ring Opening Reaction of Epoxide with Amine in the Chiral Open Space. Chem. Commun. 2008, doi: 10.1039/B714083E.

44. Tanaka, K.; Otani, K. Asymmetric Alcoholytic Kinetic Resolution of Styrene Oxide Catalysed by Chiral Metal-Organic Framework Crystals. New J. Chem. 2010, 34, 2389-2391.

45. Leong, W.L.; Vittal, J.J. One-Dimensional Coordination Polymers: Complexity and Diversity in Structures, Properties, and Applications. Chem. Rev. 2011, 111, 688-764.

46. Ouyang, X.; Chen, Z.; liu, X.; Yang, Y.; Deng, M.; Weng, L.; Zhou, Y.; Jia, Y. One-Dimensional (1D) Helical and 2D Homochiral Metal-Organic Frameworks Built from A New Chiral Octahydrobinaphthalene-Derived Dicarboxylic Acid. Inorg. Chem. Commun. 2008, 11, 948-950.

47. Yuan, G.; Zhu, C.; Xuan, W.; Cui, Y. Enantioselective Recognition and Separation by a Homochiral Porous Lamellar Solid Based on Unsymmetrical Schiff Base Metal Complexes. Chem. Eur. J. 2009, 15, 6428-6434.

48. He, Y.; Bian, Z.; Kang, C.; Cheng, Y.; Gao, L. Chiral Binaphthylbisbipyridine-Based Copper (I) Coordination Polymer Gels as Supramolecular Catalysts. Chem. Commun. 2010, 46, 3532-3534.

49. Cram, D.J.; Helgeson, R.C.; Peacock, S.C.; Kaplan, L.J.; Domeier, L.A.; Moreau, P.; Koga, K.; Mayer, J.M.; Chao, Y.; Siegel, M.G.; Hoffman, D.H.; Sogah, G.D.Y. Host-Guest Complexation. 8. Macrocyclic Polyethers Shaped by Two Rigid Substituted Dinaphthyl or Ditetralyl Units. J. Org. Chem. 1978, 43, 1930-1946.

(C) 2011 by the authors; licensee MDPI, Basel, Switzerland. This article is an open access article distributed under the terms and conditions of the Creative Commons Attribution license (http://creativecommons.org/licenses/by/3.0/). 